\title{
INTEGRAÇÃO, FLEXIBILIDADE E QUALIDADE: OS CAMINHOS PARA UM NOVO PARADIGMA PRODUTIVO
}

\author{
Roberto Antonio Martins \\ Prof. Assistente do Departamento de Engenharia de Produção da Universidade Federal de São Carlos - \\ Caixa Postal 676 - DEP/CCT/UFSCar - São Carlos - S.P. - CEP 13565-905 - Tel.: (0162) 74-8237/38 \\ José Benedito Sacomano \\ Prof. Dr. do Dept ${ }^{0}$ de Engenharia Mecânica da Escola de Engenharia de São Carlos - EESC/USP \\ Av. Dr. Carlos Botelho, 1465 - São Carlos - S.P. - CEP 13560-250 - Tel.: (0162) 72-6222 ramal 3044
}

O presente artigo apresenta os resultados de uma pesquisa de caráter exploratório realizada em quatro empresas sobre a introdução do novo paradigma produtivo mundial, tendo como objeto de estudo o sistema de Planejamento e Controle da Produção. Os resultados demonstram inexistência de uma metodologia formal para a transição de paradigma produtivo, ficando o sucesso dependente das pessoas. Além disso, persiste um mau entendimento da maneira pela qual as atividades de Planejamento e Controle da Produção gerenciam o processo produtivo. Esse entendimento abre uma grande oportunidade para os sistemas de manufatura gerenciarem de maneira mais eficaz e eficiente seus processos produtivos.

Palavras-Chaves: Paradigma, integração, flexibilidade, qualidade e planejamento.

\section{Introdução}

Algumas mudanças têm transformado a concorrência mundial, no campo da manufatura de bens industriais, nas últimas três décadas. Estas mudanças têm várias origens: a reconstrução das economias européia e japonesa, após a Segunda Guerra Mundial; o rápido desenvolvimento de novas tecnologias, como por exemplo a microeletrônica; mudanças no comportamento do consumidor, exigência de produtos com maior qualidade e menor custo; e o esgotamento da forma de organização do trabalho nos sistemas de manufatura, com o declínio da produtividade.

Essas mudanças, combinadas ou isoladamente, têm exercido grandes pressões sobre os sistemas de manufatura, obrigando-os a buscar novas formas de organização industrial para a manutenção ou o aumento de sua competitividade. Isso ocorre uma vez que os sistemas de manufatura, baseados filosoficamente no paradigma produtivo Fordista-Taylorista da produção em massa, tornaram-se improdutivos frente a essas pressões.

Urge, diante do contexto exposto, adotar um novo paradigma produtivo mundial, que suporte filosoficamente os sistemas de manufatura, na busca de novas formas de 
organização industrial mais adequadas à dinâmica do ambiente. Esse novo paradigma produtivo apoia-se em três pilares: qualidade, flexibilidade e integração.

O novo paradigma produtivo mundial tem sustentado o surgimento de novas filosofias produtivas, num quadro que se destacam três principais vertentes: a Computer-Integrated Manufacturing (CIM), os Grupos Semi-Autônomos (GSA) e a Produção Just-in-Time (JIT). Estas três vertentes - que não são excludentes entre si são novas formas de organização industrial que possibilitam a manufatura de produtos de alta qualidade, baixo custo, produzidos em pequenos lotes e com grande diversidade.

No caso brasileiro, essas pressões vêm sendo sentidas por empresas nacionais concorrendo no mercado mundial e, pelas demais, de forma mais acentuada, com a abertura da economia brasileira no início da década de 90 . Isso fez com que os sistemas de manufatura brasileiros começassem a introduzir as novas formas de organização industrial. Contudo, as condições brasileiras (instabilidade da demanda, altas taxas de inflação, alta taxa de analfabetismo, pequeno mercado consumidor etc.) são peculiares em relação às condições dos países onde emergiram essas novas formas de organização industrial.

Para o entendimento do quadro exposto acima, dentro do contexto brasileiro, uma pesquisa de caráter exploratório foi realizada no primeiro semestre de 1993, mediante estudo de caso focalizando quatro empresas brasileiras. O objetivo principal da pesquisa foi verificar in loco, com o suporte de um quadro teórico, como algumas empresas brasileiras estão buscando sua adequação ao paradigma produtivo mundial. Deste modo, pretende-se contribuir com os resultados levantados para o entendimento da situação atual pela qual está passando a maioria das empresas brasileiras. Os resultados detalhados dessa pesquisa podem ser consultados em MARTINS (1993).

\section{Pesquisa}

A pesquisa utilizou a técnica de estudo de caso, acompanhada de um quadro teórico resultante de uma extensa revisão bibliográfica sobre a mudança de paradigma produtivo e os sistemas mais comuns de Planejamento e Controle da Produção (PCP).

A técnica de estudo de caso possibilita a confrontação da teoria com a prática. Este procedimento evita o problema, colocado por THIOLLENT (1983), do excesso de empirismo (observação sem teoria) ou de formalismo (teoria sem observação do real). Desse modo, é possível atingir um bom termo entre a teoria e a prática. Para THIOLLENT (1983), o quadro teórico serve como guia para o investigador caminhar pelos labirintos da prática.

O estudo de caso foi realizado mediante entrevistas não-diretivas e observação direta, pelo pesquisador em quatro empresas. As entrevistas foram feitas com gerentes, supervisores, engenheiros, planejadores e programadores de produção. Além disso, foram levantados os fluxos de informação das atividades de Planejamento e Controle da Produção (PCP) e efetuadas visitas ao chão-de-fábrica.

Foi utilizada a técnica de entrevistas não-diretivas que, segundo THIOLLENT (1981), liberta o entrevistador e o entrevistado da rigidez imposta pelos questionários, 
possibilitando o aparecimento de novas problemáticas durante a investigação. Além disso, as informações obtidas são de melhor qualidade, uma vez que o entrevistado não é induzido a responder. As entrevistas não-diretivas foram orientadas por um roteiro que continha apenas os tópicos mais importantes a serem abordados.

\section{Objeto de Estudo}

O objeto de estudo escolhido foi o Sistema de Planejamento e Controle da Produção. O PCP, mediante a compilação de informações de várias áreas do sistema de manufatura, coordena o processo produtivo mediante a emissão de ordens de produção e ordens de compra, gerenciando o fluxo de informações e materiais, conforme ilustra a Figura 1. Portanto, o levantamento das atividades e do fluxo de informações do sistema de PCP de uma empresa fornece bons indícios de como ela está integrada e de quanto é flexível. Também é possível identificar como estão sendo buscadas novas formas de flexibilidade e integração. É interessante notar que o termo sistema de PCP, no presente artigo, refere-se a atividades ligadas por uma lógica que não necessariamente devem ficar concentradas numa única área (departamento).

Foram estudados os sistemas de PCP mais comuns encontrados na literatura e na prática das empresas: o sistema de PCP convencional, ligado ao paradigma FordistaTaylorista, que "empurra" a produção (maiores detalhes em ZACARELLI (1967) e BURBIDGE (1988)); os sistemas computadorizados MRP (Material Requirements Planning) e MRP II (Manufacturing Resources Planning) que podem estar ligados aos dois paradigmas (maiores detalhes em ORLICKY (1975), WIGHT (1984) e GROOVER (1987)); e o sistema próprio do ambiente Just-in-Time (JIT) que "puxa" a produção conforme a demanda do mercado (maiores detalhes em MONDEN (1984) e KIMURA (1987)). Naturalmente foram consideradas as combinações de técnicas de alguns sistemas, quando não filosoficamente conflitantes. 


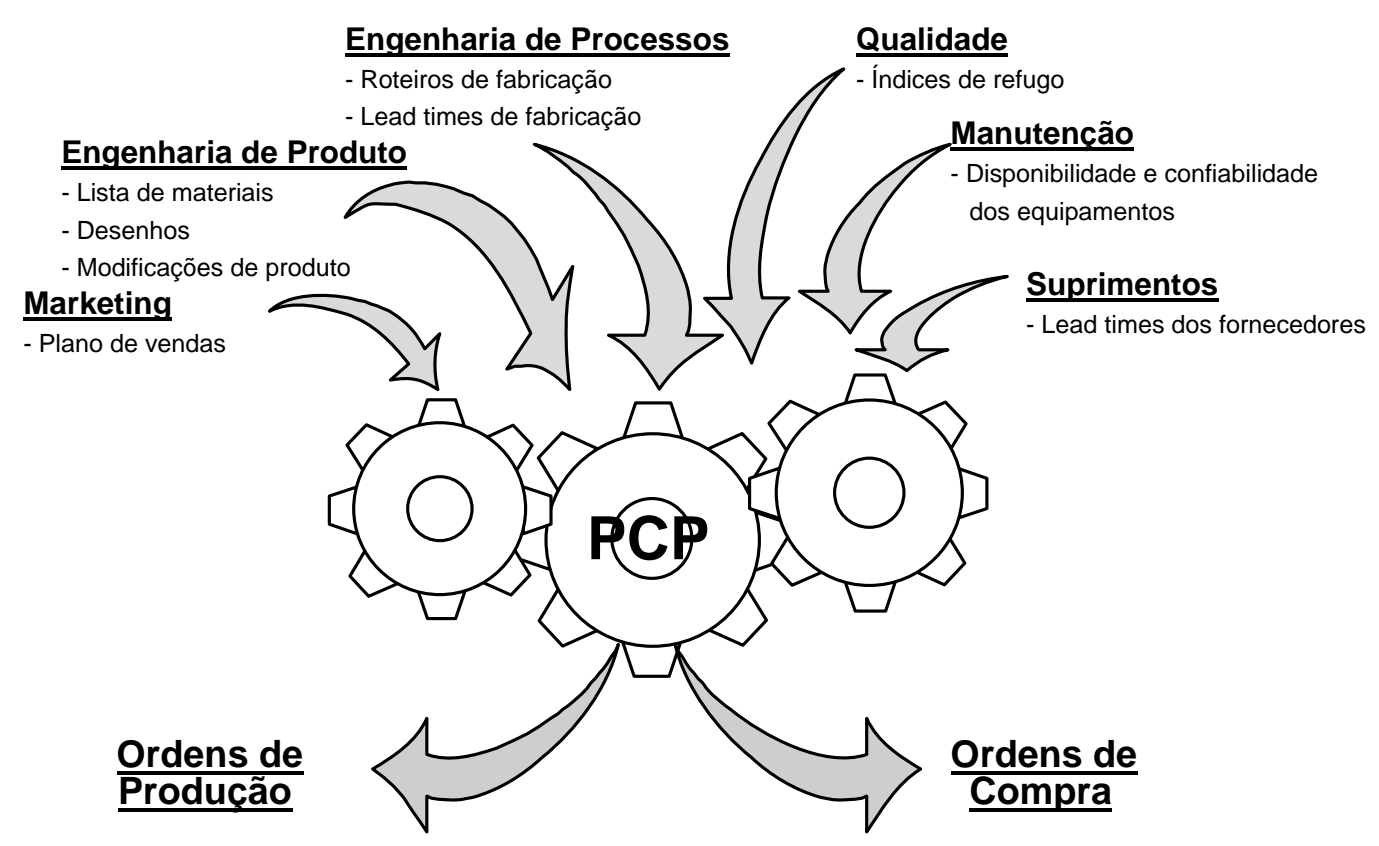

\section{A Escolha das Empresas}

Figura 1 - Fluxo de Informações do PCP.

As empresas foram escolhidas de forma que fosse possível, ao término do estudo dos casos, ter uma escala gradativa de informações qualitativas do estado atual de transição do paradigma Fordista-Taylorista para o novo paradigma. Portanto, a partir do estudo de empresas em diferentes estágios quanto à implementação de técnicas, foi possível construir uma escala gradativa, na qual, partindo de um sistema de manufatura que opera segundo o paradigma Fordista-Taylorista, e chegou-se a um sistema de manufatura operando com maior e melhor quantidade de elementos e técnicas, ligadas ao novo paradigma.

Dessa forma, pode-se ter uma noção do processo pelo qual está sendo introduzido o novo paradigma produtivo em algumas empresas, dentro da realidade brasileira, guardadas as devidas proporções, já que estes sistemas de manufatura operam em cidades diferentes e têm clientes e situações financeiras diferentes.

As empresas estudadas, aqui designadas pelas letras A, B, C e D, são descritas a seguir, de forma resumida:

Empresa A: atua no setor de eletroeletrônicos, produzindo e comercializando equipamentos da "linha branca". Está situada no interior do Estado de São Paulo e tem processos de usinagem e conformação de metais, injeção de plástico e linhas de montagem. Opera um sistema MRP e estava introduzindo Sistema Kanban e lay-out celular (minifábricas). Atua prioritariamente no mercado interno.

Empresa B: atua no setor metal-mecânico, produzindo e comercializando compressores herméticos para equipamentos de refrigeração. Está situada no interior do Estado de São Paulo, tem processos de usinagem e conformação de metais e linhas de montagem. Opera com sistema MRP e lay-out funcional, exportando mais de 50\% de sua produção para vários países. 
Empresa C: atua no setor metal-mecânico, produzindo equipamentos para indústria de cerâmica e equipamentos para indústria de processamento da borracha. Está situada no interior do Estado de São Paulo e tem processos de usinagem e conformação de metais e linha de montagem. Opera com sistema convencional de PCP e não apresenta nenhuma técnica relacionada com o novo paradigma produtivo. Atua no mercado nacional.

Empresa D: atua no setor metal-mecânico, produzindo motores de combustão interna. Está situada na região metropolitana de São Paulo e tem processos de usinagem, linhas de usinagem e montagem. Opera MRP, "puxa" a produção mediante conceito Kanban, via controle visual, lay-out celular, com minifábricas e operários multifuncionais, e nivela a produção de acordo com a demanda mensal. Atua prioritariamente no mercado interno, fornecendo para montadoras.

\section{Paradigma Fordista-Taylorista}

\subsection{Caracterização}

O paradigma Fordista-Taylorista da produção em massa começou a surgir no final do século passado e no início deste, nos Estados Unidos. Este paradigma foi constituído em três etapas distintas. A primeira etapa tem início com os trabalhos de Frederick W. Taylor, do casal Gilbreth e de outros pesquisadores. Esta etapa pode ser caracterizada pelos estudos de tarefas, pelos princípios da "Administração Científica" de Taylor e pela externalização do planejamento e controle do chão de fábrica. A segunda etapa pode ser caracterizada pela intensa aplicação da divisão do trabalho e pela determinação da cadência do trabalho mediante a criação da linha de montagem de automóveis por Henry Ford. Ele também introduziu importantes inovações no produto, que possibilitaram sua massificação. Este fato, somado à organização do trabalho introduzida, permitiu fabricar produtos padronizados, de baixo custo, devido às grandes economias de escala obtidas. A terceira etapa foi a consolidação desse paradigma através da extensão dos conceitos de Taylor e Ford para toda a corporação, efetuada por Alfred Sloan, no final da década de 20, na reconstrução da General Motors.

Para FLEURY \& VARGAS (1987:22), "Criava-se, então, uma nova estrutura administrativa na fábrica, que seria paradigma a ser seguido pelas organizações industriais". O paradigma produtivo Fordista-Taylorista foi um modelo seguido por muitas indústrias no mundo a partir da década de 30.

Conforme MARTINS (1993), o paradigma Fordista-Taylorista da produção em massa está fundamentado nos princípios da "Administração Científica" de Taylor, na organização do trabalho e na padronização do produto de Ford e na estrutura de grandes corporações de Sloan.

A aplicação dos princípios de Taylor possibilitou externalizar o planejamento e o controle do chão-de-fábrica, permitindo que sejam exercidos por um staff de engenheiros e supervisores. Além disso, a sua aplicação com extrema disciplina por Ford possibilitou a intercambiabilidade do operário, passando este a ser uma parte da 
máquina. Com a introdução da linha de montagem, foi possível a determinação precisa do ritmo de trabalho, o que não era possível para Taylor, uma vez que ele se baseava num dia ótimo de trabalho, ficando a cargo do operário o ritmo do trabalho durante o dia.

Sloan estendeu a especialização das funções e o controle externalizado para toda a organização, com intensa departamentalização e "administração por números", em que vários departamentos ou unidades operacionais são controlados à distância por meio de relatórios de desempenho.

\subsection{0 esgotamento}

Após o término da Segunda Guerra Mundial, algumas mudanças no cenário mundial começaram a modificar o ambiente interno e externo dos sistemas de manufatura, criando pressões sobre eles. Essas pressões vão levar o FordismoTaylorismo a um esgotamento como paradigma produtivo.

Alguns autores colocam de forma diferenciada os principais motivos que levaram o paradigma Fordista-Taylorista à inadequação ou ao esgotamento.

Para HAYES et al. (1988), a Segunda Guerra Mundial veio confirmar a supremacia da indústria norte-americana, baseada no paradigma Fordista-Taylorista. Nesse momento, porém, a manufatura norte-americana tinha atingido seu limite. Entretanto, os próprios americanos não se aperceberam, pois achavam que o problema de fabricar bens nos E.U.A. estava resolvido. Desse modo, os sistemas de manufatura norte-americanos passaram a privilegiar os grandes saltos (breakthroughs) em detrimento das melhorias contínuas. Estes grandes saltos seriam fruto de intensas pesquisas, realizadas nos departamentos de pesquisa e desenvolvimento, longe do chão-de-fábrica e do mercado.

Para CORIAT (1988), a própria lógica de organização do trabalho, introduzida por Taylor e consolidada por Ford, chegou ao esgotamento por si própria, tornando-se improdutiva. Além disso, com a reconstrução das economias européia e japonesa, o mercado, no fim da década de sessenta e início da de setenta, passou a ser comandado pela oferta e não mais pela demanda. Outro fator importante, é o rápido desenvolvimento tecnológico, que possibilita novos produtos e processos além de novas formas de automação da produção, a automação flexível.

Para SKINNER (1985), a rápida e intensa introdução de novos produtos - que devem ser fabricados em pequenos lotes - e o constante avanço tecnológico - que propicia novos materiais e processos - tornam inadequados e improdutivos os sistemas administrativos, a mão-de-obra extremamente especializada e a organização do trabalho dos sistemas de manufatura baseados no paradigma Fordista-Taylorista.

Desta forma, essas pressões podem ser agregadas como se fossem provenientes de três fontes externas e de uma fonte interna, conforme ilustra a Figura 2:

Mercado consumidor: passa a exigir produtos diferenciados, de alta qualidade e baixo custo. 
Concorrência: passa competir mediante a rápida e intensa introdução de novos produtos, com prazos de entrega menores e com incorporação de novas tecnologias.

Tecnologia: proporciona novos materiais, processos produtivos e novas formas de manipulação da informação, possibilitando novos produtos, máquinas e equipamentos e novas formas de organização do trabalho.

Organização do trabalho: torna-se contraproducente, principalmente, pela insatisfação dos operários.

Essas pressões transformam a forma de competir dos sistemas de manufatura. Segundo BUFFA \& SARIN (1987) e CORREAA \& GIANESI (1993), as novas dimensões de competição dos sistemas de manufatura passaram a ser: qualidade, custo, flexibilidade e confiabilidade e rapidez na entrega.

Quando colocados para competir sob essas novas dimensões, os sistemas de manufatura baseados no paradigma Fordista-Taylorista apresentam-se inadequados. Isto acontece porque eles estão baseados na produção de poucos produtos padronizados em grandes quantidades e sua estrutura organizacional é fortemente hierarquizada e departamentalizada. Assim, os sistemas de manufatura em massa não conseguem responder rapidamente aos novos impulsos do mercado e enfrentar o aumento da concorrência mundial. O processo de tomada de decisão segue um caminho extenso, o que faz com que o tempo de resposta se torne excessivamente grande, minando a competitividade do sistema. Segundo STALK JR. \& HOUT (1993), atualmente o tempo de resposta de um sistema de manufatura é um fator de competitividade. Outro fator imperativo para os sistemas de manufatura em massa, é que só é possível produzir a custos competitivos se o sistema atingir economias de escala. Estas economias de escala só são possíveis se houver padronização do produto, especialização de máquinas e equipamentos e se forem fabricados grandes lotes de produção, uma vez que sua organização industrial não permite rápidas mudanças de produtos e de quantidades a serem manufaturadas. 


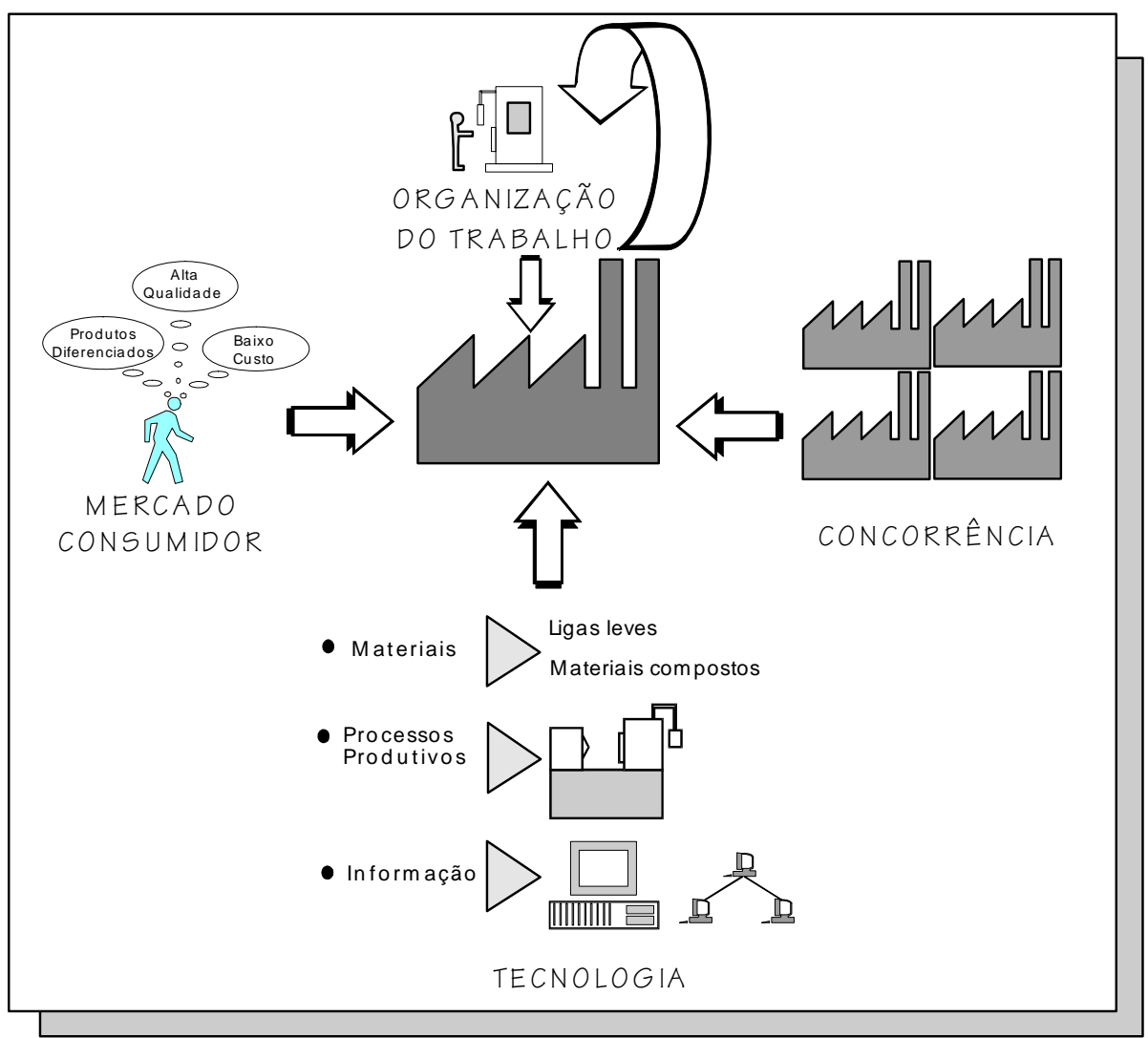

Figura 2 - Pressões Internas e Externas nos Sistemas de Manufatura. Adaptado de MARTINS (1993).

Quando os sistemas de manufatura em massa são colocados frente às novas dimensões de competição, ocorre um aumento de sua confusão operacional, aumento de seu tempo de resposta, com conseqüente diminuição de produtividade. SKINNER (1985), defende que os conceitos de gerenciamento e as técnicas utilizadas nos sistemas de manufatura fundamentados no paradigma Fordista-Taylorista são, na maioria das vezes, inadequados aos problemas a serem enfrentados atualmente. Logo, é necessário buscar novos paradigmas para os sistemas de manufatura.

\section{O Novo Paradigma Produtivo Mundial}

O novo paradigma produtivo mundial tem sua origem nas mudanças colocadas anteriormente. Reflete uma tendência que se verifica em âmbito mundial na manufatura de bens industriais. Sua efetiva implementação passa pela fundamentação de uma nova filosofia, que sustenta o surgimento de novas formas de organização da industrial implementadas mediante novas técnicas e elementos.

Para que um sistema de manufatura possa satisfazer às necessidades de seus clientes e enfrentar a concorrência, é necessário fundamentar suas atividades na busca da excelência da qualidade, nas dimensões e preço que o consumidor deseja, conforme GARVIN (1984), ter flexibilidade em seus vários tipos para responder às fontes de variabilidades tanto internas como externas, conforme BECKMAN (1990), e 
estar integrado para responder rapidamente e de forma econômica aos novos impulsos.

A qualidade deve ser incorporada à cultura do sistema de manufatura, desde o planejamento estratégico até a rotina de trabalho de uma recepcionista. MERLI (1993) sugere um interessante modelo de planejamento estratégico abrangente, que considera a qualidade na estratégia de negócio do sistema de manufatura.

É necessário um treinamento intensivo de todos os funcionários, tanto na filosofia da qualidade quanto nas técnicas disponíveis. O autocontrole deve ser desenvolvido para o controle da qualidade na fonte, evitando-se assim a propagação de erros na cadeia produtiva.

Outro fator importante é o foco no cliente, mediante a criação da relação clientefornecedor externa e interna. No terreno externo, coloca o cliente como uma extensão do sistema de manufatura, isto é, o último elo quando recebe o produto ou serviço final, e o primeiro quando dita suas necessidades. No domínio interno, aproxima e integra os processos, possibilitando o diálogo sobre o que é necessário, evitando erros e desperdícios. Segundo SCHONBERGER (1992), cria-se desse modo uma cadeia de clientes e fornecedores fortemente integrada.

A flexibilidade a ser priorizada ou potencializada depende da estratégia adotada pelo sistema de manufatura. A flexibilidade deve estar presente, principalmente, nos equipamentos e na forma de desenvolvimento de novos produtos, devido às novas formas de concorrência e necessidades dos consumidores. Nos equipamentos, pela adoção de equipamentos de automação flexível, ou de sistema de troca rápida de ferramentas. No desenvolvimento de novos produtos pela aplicação de computadores sistemas CAD/CAE (Computer-Aided Design/Computer-Aided Engineering) - ou técnicas de Engenharia Simultânea. O importante é responder rapidamente às mudanças do mercado consumidor e às exigências do consumidor.

Outro fator importante a ser considerado é a flexibilidade da mão-de-obra, tanto na área administrativa quanto no chão-de-fábrica. No nível administrativo, é interessante desenvolver uma visão global dos processos da empresa, mediante rodízio de cargos. No nível dos operários, o interessante é a qualificação para operar vários equipamentos, a capacidade para executar pequenas tarefas de manutenção, programação de máquinas de controle numérico, controle da qualidade e resolução de problemas. Para BECKMAN (1990), se variabilidade é o nome do jogo, flexibilidade é a resposta.

Considerando o tempo como um fator de competitividade, conforme colocado anteriormente, e a informação como um insumo disparador de todos os processos dentro do sistema de manufatura, torna-se vital para a competitividade do sistema de manufatura o modo de circulação da informação.

Para a informação circular rapidamente e de forma consistente, sem redundância e com qualidade, são necessárias novas formas de integração para os sistemas de manufatura. É preciso derrubar as "paredes" organizacionais erguidas entre as "ilhas de informação" em que se transformaram os departamentos com a adoção da departamentalização das organizações. 
Deve ser incentivado o trabalho em equipe, tanto dentro das áreas quanto, e principalmente, entre as áreas. Essa integração melhora a qualidade das atividades e aumenta a flexibilidade.

Um forte fator de integração são os sistemas de informação. Eles devem viabilizar um fluxo rápido e atualizado das informações dentro do sistema de manufatura, sem redundância nem falta. GUNN (1987) coloca a informação como o principal fator de integração.

CORIAT (1988) defende o surgimento de novas formas de integração nos sistemas de manufatura. No plano tecnológico, mediante a integração dos sistemas de informação; no plano de seqüência de operações, mediante a integração dos processos produtivos; e no plano organizacional, mediante o rompimento das barreiras entre as áreas funcionais do sistema de manufatura.

Para RIIS (1992), as novas formas de concorrência exigem dos sistemas de manufatura uma visão sistêmica da manufatura. A visão sistêmica da manufatura criará novas formas de integração no terreno funcional, no dos sistemas de informação e no organizacional, possibilitando ao sistema de manufatura suprir as necessidades de seus consumidores.

Portanto, uma nova filosofia produtiva deve guiar a implantação de novas formas de organização industrial nos sistemas de manufatura de modo a adequá-los à concorrência e manter sua competitividade.

Das novas formas de organização industrial surgidas destacam-se, na literatura, a Produção Just-in-Time (maiores detalhes em OHNO (1988), MONDEN (1984) e KIMURA (1987)), a Computer-Integrated Manufacturing (maiores detalhes em GROOVER (1987), GUNN (1987) e KOCHAN (1986)), e os Grupos SemiAutônomos (maiores detalhes em ORSTMAN (1984), COLE (1989) e MARX (1992)).

Não é intuito desse artigo detalhar estas novas formas de organização industrial. Entretanto, cabe destacar que, de maneira diferenciada, cada uma das três formas buscou alternativas para conseguir a produção de bens de alta qualidade mediante novas formas de integração e flexibilidade.

A Produção JIT aplica fortemente o estudo de tarefas e o ritmo da produção, porém valorizando o operário e desenvolvendo nele a capacidade de resolver pequenos problemas e dar sugestões de melhoria. O fluxo de produtos da linha de montagem é estendido para todas as etapas do processo produtivo, de modo a sincronizar a manufatura, tendo como base os pulsos da demanda que "puxa" a produção, conforme HALL (1988). Segundo OHNO (1988), a meta principal é a redução de toda e qualquer atividade que não agregue valor ao produto.

A Computer-Integrated Manufacturing (CIM) busca, via aplicação intensa de uma ferramenta (computadores e máquinas/equipamentos com microeletrônica embarcada), constituir novas formas de integração e flexibilidade. Apesar de ser dispendida muita atenção aos computadores, é interessante analisar um sistema de manufatura integrado por computadores como um arranjo lógico (sistema) do processo de transformação (manufatura) que está totalmente ligado (integrado) por meio de uma ferramenta (computadores), MARTINS (1993). Vale a pena destacar que a 
intensa utilização de tecnologia não é suficiente. É preciso mudar a filosofia de gerenciamento do sistema. Neste sentido é interessante a pesquisa comparativa entre sistemas flexíveis de manufatura norte-americanos e japoneses, feita por JAIKUMAR (1986). Com praticamente os mesmos equipamentos, os japoneses tinham produtividade e competitividade muito superiores à dos norte-americanos, fruto de uma filosofia administrativa diferenciada.

Os Grupos Semi-Autônomos são uma alternativa à organização do trabalho de Taylor e Ford. Isto é alcançado mediante a combinação de elementos da produção artesanal e tecnologia, de forma a atingir alta qualidade, novas formas de integração no chão-de-fábrica (grupos de operários responsáveis pela fabricação total de um produto) e flexibilidade, graças à multifuncionalidade da mão-de-obra e equipamentos. Além disso, procura-se eliminar a insatisfação com o trabalho, introduzida por sua excessiva divisão e pelas linhas de montagem. Os GSA's são resultado dos trabalhos da corrente sócio-técnica de organização do trabalho.

\section{Conclusões}

A pesquisa conduziu a duas importantes conclusões. A primeira conclusão pode parecer fora do objetivo inicial da pesquisa. Contudo, face à sua importância, ela não pode ser omitida. Ela é resultado do objeto de estudo escolhido, o Sistema de PCP. A segunda conclusão diz repeito ao objetivo principal da pesquisa, ou seja, a mudança de paradigma produtivo em algumas empresas brasileiras. Ambas são apresentadas a seguir.

\subsection{A falta de base filosófica da gerência}

O levantamento do fluxo de informações das atividades de PCP e as entrevistas com gerentes e supervisores deste setor das empresas apresentaram alguns fatos analisados a seguir.

Falta de entendimento da lógica do processo decisório do PCP. A estrutura do processo decisório do PCP, como está representada na Figura 3, apresentou - nas empresas A, B e C - hierarquia indefinida, ausência de denominação, planejamento de capacidade inexistente, pouca ênfase na programação e no seqüenciamento da produção, fraco controle da produção e técnicas conflitantes (pertencentes a paradigmas diferentes) operando num mesmo sistema. Esses fatos levam a concluir que não existe um perfeito entendimento do modo pelo qual as atividades de PCP coordenam o chão-de-fábrica, como ilustrado na Figura 1.

Para exemplificar, as empresas B e C não têm plano agregado de produção. As empresas $\mathrm{C}$ e D realizam essa atividade utilizando somente o julgamento pessoal como técnica, sem incluir no plano nenhuma consideração financeira, apenas níveis de estoque e mão-de-obra. Outro fato alarmante é o modo pelo qual são realizadas as atividades de programação e controle da produção. Essas atividades, nas empresas A, B e C, não têm a atenção que merecem, para enfrentar a dinâmica da economia brasileira. Não contam com nenhuma técnica especial e nem mesmo com novas 
tecnologias, como o acompanhamento da ordem de produção por código de barras, praticado somente pela empresa $\mathrm{D}$.

Mistura de técnicas pertencentes a paradigmas diferentes. Foram encontradas nas empresas A e B técnicas de planejamento de materiais conflitantes entre si. Nessas empresas, alguns itens de demanda dependente no MRP eram controlados pela técnica do Ponto de Reencomenda, o que é um erro, segundo ORLICKY (1975) e WIGHT (1984), já que, com relação a esses itens, é possível determinar precisamente as necessidades. Isto pode levar, na melhor das hipóteses, a um fraco aproveitamento do potencial proporcionado pelas novas técnicas.

Implementação isolada de elementos de novas formas de organização da produção. A empresa A estava implementando elementos isolados da Produção Justin-Time, tais como lay-out celular com a configuração de minifábricas e Sistema Kanban, porém não tinha garantia de qualidade nem troca rápida de ferramentas. Segundo MONDEN (1984), o Sistema Kanban é o sistema de informação de um ambiente JIT, mas sua implementação deve ser precedida pela de técnicas de garantia da qualidade e troca rápida de ferramentas, para que seja possível "puxar" a produção, de modo a proporcionar flexibilidade com pequenos lotes de produção.

Portanto, um perfeito entendimento do encadeamento lógico das atividades de PCP pode proporcionar ganhos aos sistemas de manufatura, sem exigir grandes investimentos. Esse entendimento possibilitará um melhor gerenciamento do processo produtivo.

Esses fatos, somados aos resultados semelhantes coletados por SACOMANO (1990) e RESENDE (1989), que investigaram os efeitos da introdução de novas formas de organização da produção nas atividades de PCP, permitem concluir que ainda falta formação filosófica aos gerentes e supervisores. Esta formação filosófica que é o entendimento das transformações da manufatura e do surgimento de um novo paradigma produtivo e suas novas formas de organização industrial, bem como do encadeamento lógico das atividades de PCP no gerenciamento do processo produtivo pode potencializar os ganhos das novas técnicas ligadas ao novo paradigma, além de orientar as adaptações necessárias para assegurar seu perfeito funcionamento na realidade brasileira.

Enquanto persistir essa deficiência de formação filosófica, os resultados serão, no máximo, um rendimento muito inferior ao que se poderia esperar das técnicas e elementos implementados, seja por implementação incompleta, seja por falta de adaptação ao caso brasileiro; e, no mínimo, descrença no fato de que essas técnicas sejam passíveis de implementação.

\subsection{A mudança de paradigma produtivo: um processo ordenado, lento e necessário}

O objeto de estudo forneceu indícios do modo pelo qual está sendo introduzido o novo paradigma produtivo mundial, somente no tocante a duas dimensões flexibilidade e integração. A questão da qualidade extrapola o âmbito das atividades de PCP e suas interfaces, uma vez que ela permeia todas as atividades de um sistema 
de manufatura. Sendo assim, é necessária a condução de pesquisas específicas sobre a questão da qualidade no novo paradigma produtivo.

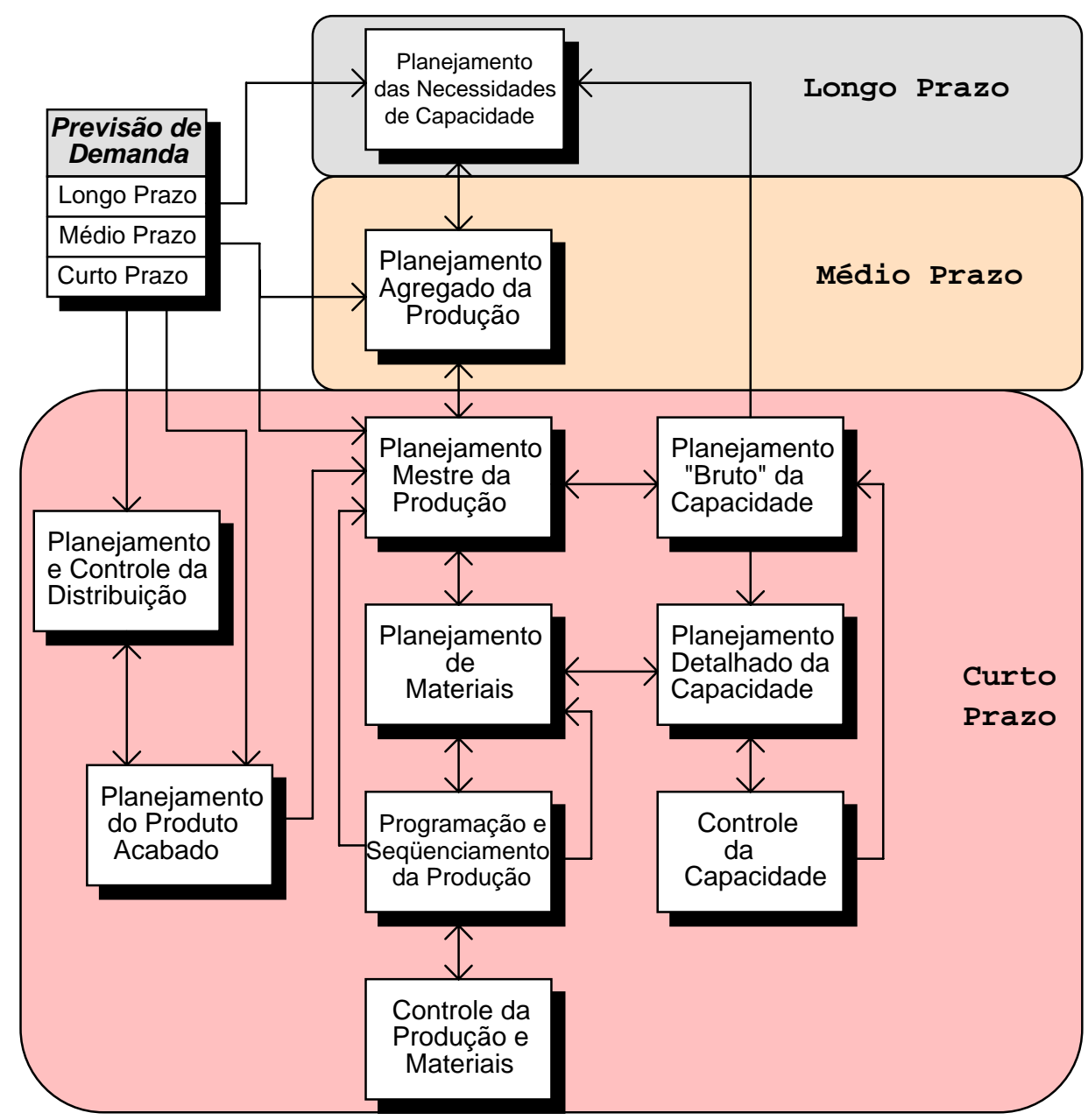

Figura 3 - Estrutura do Processo Decisório do Planejamento e Controle da Produção. Adaptado de SILVER \& PETERSON (1985).

Quanto à flexibilidade e integração, a realidade brasileira - instabilidade econômica, baixo nível de qualificação da mão-de-obra, fornecedores despreparados etc. - tem imposto diferentes necessidades de flexibilidade e integração aos sistemas de manufatura pesquisados. As necessidades de flexibilidade para responder a certas fontes de variabilidade e as novas formas de integração em seus vários níveis, resultados da pesquisa de MARTINS (1993), estão ilustradas nas Tabelas 1 e 2 respectivamente.

Analisando a Tabela 1, pode-se verificar que, na introdução de várias formas de flexibilidade, alguns procedimentos são corretos e outros são apenas paliativos, que tendem esgotar-se com o tempo. A utilização de horas-extra para suprir variações do volume de produção, decorrentes de flutuações na demanda, por um curto período mostra-se eficiente, porém, quando adotada por um longo período, traz problemas de 
fadiga da mão-de-obra, que acarreta declínio da qualidade e da produtividade do sistema de manufatura, conforme verificado em todas empresas pesquisadas.

Tabela 1 - Busca de Flexibilidades nos Sistemas de Manufatura Estudados. Fonte: MARTINS (1993).

\begin{tabular}{|c|c|c|}
\hline $\begin{array}{c}\text { FONTE DE } \\
\text { VARIABILIDADE }\end{array}$ & $\begin{array}{l}\text { NECESSIDADE DE } \\
\text { FLEXIBILIDADE }\end{array}$ & $\begin{array}{c}\text { MEIOS } \\
\text { UTILIZADOS } \\
\end{array}$ \\
\hline $\begin{array}{l}\text { Oscilação no volume da } \\
\text { demanda }\end{array}$ & $\begin{array}{l}\text { para flutuações de carga } \\
\text { de trabalho }\end{array}$ & Horas-extra da mão-de-obra \\
\hline $\begin{array}{l}\text { Oscilação no volume da } \\
\text { demanda }\end{array}$ & $\begin{array}{l}\text { para suportar erros de } \\
\text { previsão }\end{array}$ & $\begin{array}{l}\text { Introdução de períodos } \\
\text { "firmes" e "abertos" }\end{array}$ \\
\hline $\begin{array}{l}\text { Aumento da variedade } \\
\text { dos produtos } \\
\text { demandados }\end{array}$ & $\begin{array}{l}\text { para mudanças de } \\
\text { produtos }\end{array}$ & $\begin{array}{l}\text { Estoques de produtos } \\
\text { acabados e introdução de } \\
\text { elementos da produção } \\
\text { "enxuta" }\end{array}$ \\
\hline $\begin{array}{l}\text { Aumento da variedade } \\
\text { dos produtos } \\
\text { demandados }\end{array}$ & $\begin{array}{l}\text { para montagem de } \\
\text { máquinas para novas } \\
\text { peças }\end{array}$ & $\begin{array}{l}\text { Troca rápida de ferramentas } \\
\text { e equipamentos de } \\
\text { automação flexível }\end{array}$ \\
\hline $\begin{array}{l}\text { Suprimentos (qualidade } \\
\text { e prazos de entrega) }\end{array}$ & $\begin{array}{l}\text { para compensar o mau } \\
\text { funcionamento do } \\
\text { sistema (fornecedores) }\end{array}$ & $\begin{array}{l}\text { Estoques de matérias- } \\
\text { primas, peças e } \\
\text { subconjuntos }\end{array}$ \\
\hline
\end{tabular}

A introdução de períodos "firmes" e períodos "abertos" no planejamento da produção não apresentou uma sistemática em nenhuma das empresas visitadas. $\mathrm{O}$ mecanismo foi implementado das mais diversas formas, ou seja, existe necessidade de um estudo para sistematização desse procedimento para sua potencialização. As atividades de PCP devem adaptar-se à nova dinâmica, aplicando conceitos da Engenharia Simultânea. Isto deve ser alvo de novos estudos e pesquisas.

O estoque de matérias-primas, em períodos de aceleração inflacionária ou de grande especulação, pode parecer um bom negócio. Porém, com a estabilização da economia, esta prática passará a onerar muito as empresas. Em conseqüência, a busca de flexibilidade por meio da formação de estoques tende a ser um caminho pouco produtivo.

Deve-se privilegiar a busca de flexibilidade, conforme visto na empresa $\mathrm{D}$, via a introdução de elementos JIT ligados ao novo paradigma produtivo. A troca rápida de ferramentas nesta empresa permite rápida mudança do mix de produção sem aumento de custos. Nesta mesma empresa, o nivelamento da produção - produção diária de cada produto proporcional ao total mensal - possibilitava responder de forma uniforme às variações na demanda sem formação de estoques desnecessários.

Analisando a Tabela 2, pode-se verificar que a busca de integração apresenta, basicamente, os mesmos problemas da introdução de flexibilidade, ou seja, algumas soluções indicam um caminho certo e outras necessitam de maiores estudos. 
Tabela 2 - Busca de Integração nos Sistemas de Manufatura Estudados. Adaptado de MARTINS (1993).

FORMAS DE INTEGRAÇÃO

Tecnologia da Informação

Arranjo dos Processos Produtivos

Arquitetura Organizacional

\section{MEIOS UTILIZADOS}

- Código de barras

- Transferência manual de dados micro/mainframe

- Sistema MRP

- Lay-out celular

- Reuniões periódicas entre PCP, Vendas e Manufatura

- Contatos informais PCP-Clientes e PCPFornecedores

Por exemplo, a busca de integração por meio de tecnologia de informação, utilizando código de barras para acompanhamento das ordens de fabricação, na Empresa D, mostrou-se muito eficiente. Pela aplicação da tecnologia é possível evitar que o seqüenciamento determinado pelo PCP seja alterado: o sistema só aceita o apontamento na mesma seqüência em cada um dos postos de apontamento. Além disso, é possível ter um acompanhamento preciso, remotamente, sobre o andamento das ordens no chão-de-fábrica. Contudo, a integração dos microcomputadores com os computadores de grande porte apresentou-se fraca. A transferência de dados, nas empresas A, B e D, era feita manualmente, já que uma parte do planejamento era realizado em planilhas eletrônicas nos microcomputadores e outra nos computadores de grande porte.

No nível de arranjos produtivos, a utilização de lay-out celular possibilita uma forte integração entre processos e entre os operários responsáveis pela célula. Pode-se obter ganhos consideráveis de espaço, qualidade e produtividade. Porém, conforme SACOMANO (1990), um problema para introdução do lay-out celular é a necessidade dde contar com operários multifuncionais. A empresa $\mathrm{C}$ enfrentava exatamente esse problema na introdução de células de produção.

No nível organizacional, a situação mostrou-se mais complicada. A integração PCP-Vendas, PCP-Suprimentos e PCP-Manufatura era obtida mediante de reuniões periódicas nas quais era acordado um plano de vendas realizável. Esse procedimento mostra-se muito eficiente, porém não existe uma sistematização para ele. Na empresa A, essas reuniões não envolviam Suprimentos. Na empresa $\mathrm{B}$, a reunião envolvia todos. Na empresa D, Vendas não participava. É necessário que pesquisas sejam feitas para a formalização desse procedimento de maneira a integrar as grandes áreas envolvidas no gerenciamento cotidiano do sistema de manufatura.

Na empresa D, por seu estágio mais avançado, o PCP sentia necessidade de se integrar mais com fornecedores e clientes, após o contato comercial, para poder 
aproveitar melhor a flexibilidade disponível no chão-de-fábrica. Era preciso estender as transformações do chão-de-fábrica para as outras áreas do sistema de manufatura.

Do quadro exposto acima, pode-se concluir que a busca de novas formas de integração e flexibilidade segue, na maioria dos casos, um processo descoordenado, apresentando desvios perigosos que representam alto risco na busca de adequação ao novo paradigma produtivo mundial.

Alguns fatos ilustram esse risco: a presença de técnicas conflitantes de planejamento de materiais é uma evidência de deficiência filosófica e não de adaptação; a introdução pontual de elementos da Produção JIT; e o não entendimento do encadeamento lógico do processo decisório do PCP. Corre-se o risco de desperdiçar tempo e recursos, tão escassos, numa busca de introdução de novas técnicas sem o necessário entendimento prévio de seu contexto filosófico.

Busca-se, aparentemente, copiar de maneira errada modelos externos ou dos concorrentes, na esperança de grandes retornos a curto prazo. Um exemplo foi encontrado no estudo da empresa C, que, por ordem dos proprietários, procurou reduzir estoques sem a devida adequação dos fornecedores, que não cumpriam prazos, e sem sincronização das atividades internas, obtendo como resultado, o aumento do tempo total de fabricação, pela falta de peças e subconjuntos. Constatou-se a inexistência de uma metodologia para mudança de paradigma, sendo o êxito dependente de características das pessoas que coordenam ou disparam o processo de mudança.

Portanto, existe a necessidade de pesquisas que gerem uma metodologia básica, que contemple as etapas mínimas para a mudança de paradigma. Não se pode alimentar a ilusão de introdução rápida dessas novas formas de organização industrial. A mudança de paradigma produtivo não pode ser um passo abrupto, deve ser entendida, planejada e guiada, pois, caso contrário, pode trazer muitos prejuízos para o sistema de manufatura, na forma de baixa produtividade e perda de market share. A Figura 4 sugere como pode ser a mudança de paradigma produtivo. 


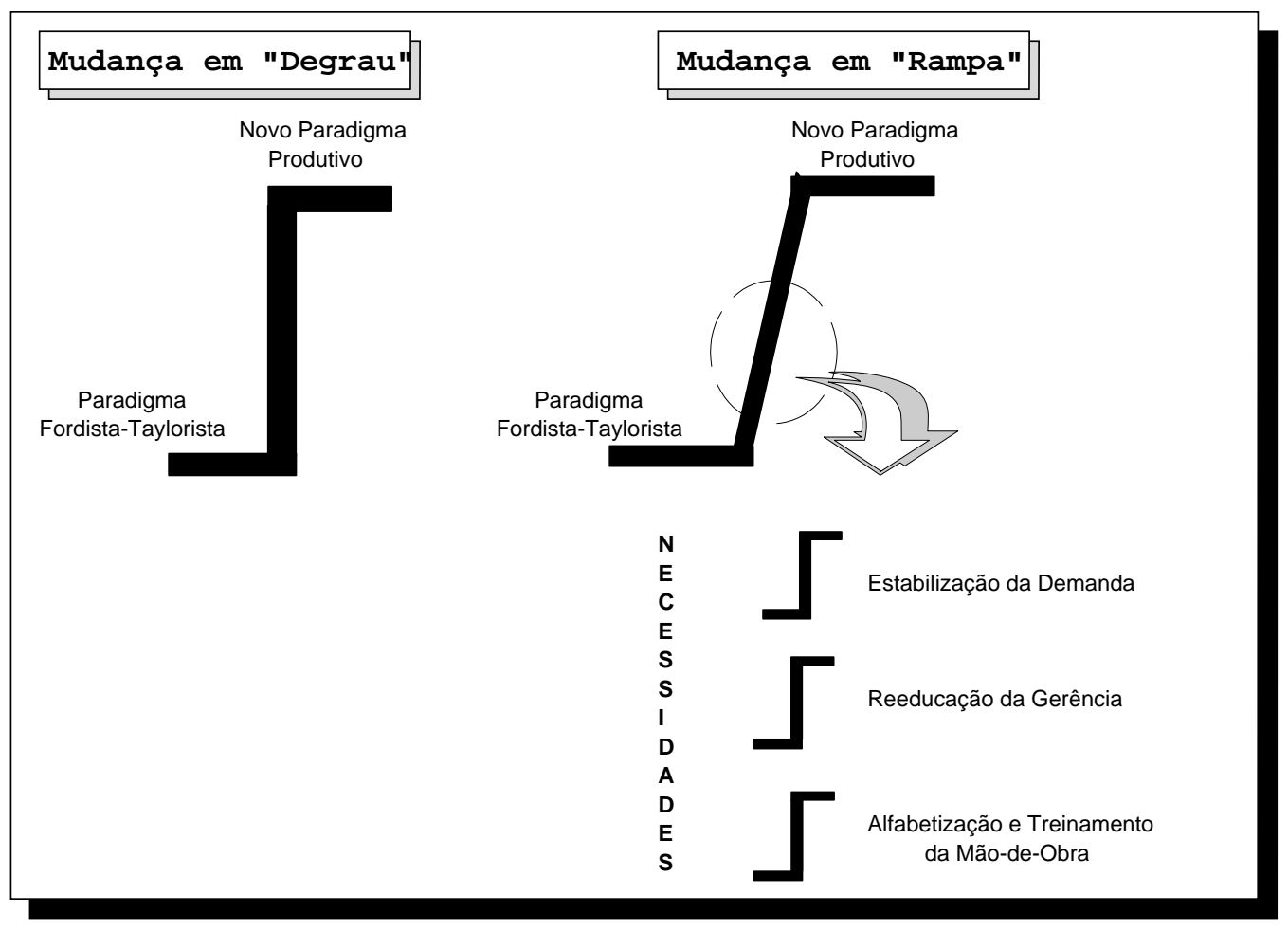

Figura 4 - Mudança de Paradigma Produtivo.

A mudança em "rampa" planejada exige que, momentaneamente, num dado instante, o sistema de manufatura conviva com métodos de gerenciamento pertencentes a paradigma diferentes. Entretanto, essa convivência é planejada e tem sua duração programada.

Naturalmente que a mudança em "rampa" deve ser decomposta numa série de pequenos "degraus" (necessidades), que dependem tanto dos sistemas de manufatura quanto de políticas governamentais. Entre essas necessidades estão a estabilização da demanda, a redução das taxas de juros, a alfabetização dos operários, a reeducação da média e alta gerência, a política de redistribuição de renda etc.

A instabilidade da demanda é uma característica brasileira, não encontrada em nenhum dos países nos quais surgiram as novas formas de organização industrial. Todos esses países (Japão, Estados Unidos, Alemanha e Suécia) contavam com um grande mercado interno e demanda estável. É necessária uma reflexão sobre a necessidade de estabilizar a demanda ou adequar os sistemas de PCP para responderem adequadamente a uma demanda instável. As altas taxas de juros brasileiras inibem os investimentos no setor produtivo, fazendo com que os agentes econômicos prefiram a segurança e o rápido ganho das aplicações financeiras. Os sistemas de manufatura não podem esperar pelo Estado para suprir a necessidade de alfabetização dos operários. Cada vez mais devem-se buscar meios para educar e treinar a mão-de-obra para resolver pequenos problemas, propor melhorias e operar equipamentos cada vez mais sofisticados.

O entendimento filosófico da mudança de paradigma é imperativo para que não sejam desperdiçados preciosos recursos na implementação errônea ou localizadas de 
técnicas. Naturalmente, muitos dessas necessidades vinculam-se à vontade política de se criar um projeto para o país.

Finalmente, é interessante lembrar que a década de setenta foi perdida na busca de um novo paradigma, graças à ilusão do milagre econômico que acentuou a filosofia do desperdício, acompanhado de fluxos de caixa permanentemente positivos. Na década de oitenta, prevaleceu a forte crise econômica com altas taxas inflacionárias e seguidos choques econômicos, fazendo o fluxo de caixa merecer maior atenção que o fluxo de materiais. Assim sendo, não há tempo a perder. É necessário encontrar uma nova forma de organização industrial que, de forma eficaz e eficiente, alavanque o crescimento do país.

\section{Referências Bibliográficas:}

BECKMAN, S.L.: "Manufacturing flexibility: next source of competitive advantage". In: MOODY, P.: Strategic manufacturing. Richard D. Irwin, Inc., p.107-132., 1990.

BUFFA, E.S. \& SARIN, R.K. Modern production/operations management. John Wiley \& Sons, Inc., New York, (834 p.), 1987.

BURBIDGE, J. L. Planejamento e controle da produção. 2.ed. Atlas, São Paulo, (556 p.), 1988.

COLE, R. E. Strategies for learning. Berkeley, University of California Press, (338 p.), 1989.

CORIAT, B.: "Automação programável: novas formas e conceitos de organização da produção". In: SCHMITZ, H. \& CARVALHO, R. (orgs.) Automação, competitividade e trabalho: a experiência internacional. São Paulo, Hucitec, p. 13-61, 1988.

CORREAA, H.L. \& GIANESI, I.G. Just in time, MRP II e OPT- um enfoque estratégico. Atlas, São Paulo, (186 p.), 1993.

FLEURY, A.C.C. \& VARGAS, N.: "Aspectos conceituais". In: FLEURY, A.C.C. \& VARGAS, N. (org.): Organização do trabalho, 2.ed.. Atlas, p.17-37, 1987.

GARVIN, D.A.: "What does product quality really mean?". Sloan Management Review, p.25-43, Fall/1984.

GROOVER, M.P.: Automation production systems and computer integrated manufacturing. Englewood Cliffs, Prentice-Hall, (808 p.), 1987. .

GUNN, T. Manufacturing for competitive advantage - becoming a world class manufacturer. Ballinger Publishing Co., New York, (224 p.), 1987.

HALL, R.W. Excelência na manufatura, 3.ed.. IMAM, São Paulo, 1988.

HAYES, R.H.; WHEELWRIGHT, S.C.; CLARK, K.B.: Dynamic manufacturing. Free Press, New York, (429 p.), 1988.

JAIKUMAR, R.: "Postindustrial manufacturing". Harvard Business Review, v.64, n.6, p.69-76, Nov./Dec. 1986. 
KIMURA, O.: "The Toyota production system: today and tomorrow". In: YOSHIKAWA, H. \& BURBDIGE, J.L. (orgs.): New technologies for production management system. Elsevier Science, Amsterdam, p.3-18, 1987.

KOCHAN, D. CAM - developments in computer-integrated manufacturing. Springer-Verlag, Berlin, (289 p.), 1986.

MARTINS, R. A.: Flexibilidade e integração no novo paradigma produtivo mundial: estudos de casos. Dissertação de Mestrado, EESC/USP, São Carlos, (137 p.), 1993.

MARX, R.: "Processo de trabalho e grupos semi-autônomos: a evolução da experiência sueca de Kalmar aos anos 90". Revista de Administração, v.32, n.2, p.36-43, Abr./Jun. 1992.

MERLI, G.: Eurochallenge - the TQM approach to capturing global markets. IFS Ltd., Bedford, U.K., (208 p.), 1993.

MONDEN, Y. Sistema Toyota de produção. São Paulo, IMAM, (141p.), 1984.

OHNO, T.: Just-in-time for today and tomorrow. Productivity Press, Cambridge, Mass., (145 p.), 1988.

ORLICKY, J.: Material requirements planning. McGraw-Hill, New York, (292 p.), 1975.

ORTSMAN, O.: Mudar o trabalho. Fundação Calouste Gulbenkian, Lisboa, (410 p.), 1984.

RESENDE, M.O.: Planejamento e controle da produção: teoria e prática da indústria mecânica no Brasil. Tese de Doutorado, EESC/USP, São Carlos, 1990.

RIIS, J.O.: "Integration and manufacturing strategy". Computers in Industry, v.19, n.1, p.37-50, April 1992.

SACOMANO, J.B.: Uma análise da estrutura funcional do planejamento e controle da produção e suas técnicas auxiliares. Tese de Doutorado, EESC/USP, São Carlos, (378 p.), 1990.

SCHONBERGER, R. J.: Construíndo uma corrente de clientes. Pioneira, São Paulo, (336 p.), 1992.

SILVER, E.A. \& PETERSON, R.: Decision systems for inventory management and production planning. John Wiley \& Sons, Inc., New York, (722 p.), 1985.

SKINNER, W.: Manufacturing - a formidable competitive weapon. John Wiley \& Sons, Inc., New York, (330 p.), 1985.

STALK JR., G. \& HOUT, T.M.: Competindo contra o tempo. Atlas, São Paulo, (314 p.), 1993.

THIOLLENT, M.: Crítica metodológica, investigação social e enquete operária. 2.ed.. Polis, São Paulo, (270 p.), 1981.

THIOLLENT, M.: "Problemas de Metodologia", In: Fleury, A. C. C. \& Vargas, N. (orgs.) Organização do trabalho, 2.ed.. Atlas, São Paulo, p. 54-83, 1983.

WIGHT, O.: Production and inventory management in the computer age. Van Nostrand Reinhold, New York, (284 p.), 1984.

ZACARELLI, S.B.: Programação e controle da produção. Pioneira, São Paulo, (293 p.), 1967. 


\title{
INTEGRATION, FLEXIBILITY AND QUALITY: THE WAY TO A NEW PRODUCTIVE PARADIGM
}

\begin{abstract}
The objective of this paper is to report some results of exploratory research carried out in four Brazilian companies. The subject of research is the introduction of a new world-wide productive paradigm. The object of study was the Production Planning and Control Systems. The findings show that there is not a formal methodology for the transition of the productive paradigm. The success depends on people. Moreover, there is a misunderstanding of how the activities of Production Planning and Control manage the production process. Such an understanding is a great opportunity for manufacturing systems to manage better their productive processes.
\end{abstract}

Key-words: Paradigm, integration, flexibility, quality, planning. 